\title{
Seafloor positioning system with GPS-acoustic link for crustal dynamics observation-a preliminary result from experiments in the sea-
}

\author{
Koichiro Obana*, Hiroshi Katao, and Masataka Ando** \\ Disaster Prevention Research Institute, Kyoto University, Gokasho, Uji, Kyoto 611-0011, Japan
}

(Received March 19, 1999; Revised May 17, 2000; Accepted May 18, 2000)

\begin{abstract}
Many active plate boundaries, such as mid-ocean ridges and trenches, are under the sea. Seafloor crustal deformation data will contribute significantly to understanding the nature of the tectonic processes at these plate boundaries. We have developed a seafloor positioning system with a GPS-acoustic link. This system consists of two main components; (1) the surface positioning by differential GPS to on-land reference and (2) the precise acoustic ranging using the $\mathrm{M}$-sequence between the surface and seafloor references. The position and attitude of the surface GPS-acoustic link unit are determined from the GPS observations. Simultaneously, the acoustic ranging between the surface unit and seafloor references are carried out. The positions of the seafloor references are determined from these observations and a sound-speed structure model of the seawater. We performed preliminary seafloor positioning experiments. In these experiments, simple 1-D structure models are assumed for the sound-speed in the sea. The results show that the positions of the seafloor references are estimated with an accuracy on order of $10 \mathrm{~cm}$. The residuals for acoustic ranging imply that there are systematic differences between the assumed and real sound-speed structure. It is necessary to reduce the uncertainties of sound-speed structures for more accurate positioning.
\end{abstract}

\section{Introduction}

It is thought that most of the deformations which results from plate motion takes place at the edges or boundaries of a plate, under the concept of rigid plate tectonics. For example, Heki et al. (1997) reported the occurrence of transient crustal movements following a typical inter-plate earthquake in December 1994 at the Japan Trench. They showed that these movements are caused by a slow slip on the fault plane, and that the amount of seismic moment released by this slow slip is comparable to that released during the high-speed rupture in the earthquake. The existence of slow slip is derived from on-land observations. If we can measure crustal movements much closer to the source region of tectonic events, the data will contribute significantly to understanding the nature of tectonic processes at plate boundaries. However, many of the active plate boundaries, such as mid-ocean ridges and trenches, are under the sea. Seafloor observations are important for monitoring phenomena taking place around plate boundaries.

Some observation systems and methods have been suggested for seafloor geodetic observations. The tilt measurement is thought to be one of the effective methods (e.g.,

*Present address: Frontier Research Program for Subduction Dynamics, Japan Marine Science and Technology Center, 2-15 Natsushima-cho, Yokosuka 237-0061, Japan.

** Present address: Research Center for Seismology and Volcanology, Graduate School of Science, Nagoya University, Furo-cho, Chikusa-ku, Nagoya 464-8602, Japan.

Copy right(C) The Society of Geomagnetism and Earth, Planetary and Space Sciences (SGEPSS); The Seismological Society of Japan; The Volcanological Society of Japan; The Geodetic Society of Japan; The Japanese Society for Planetary Sciences.
Sakata et al., 1981; Shimamura and Kanazawa, 1988; Anderson et al., 1997). Shimamura and Kanazawa (1988) installed the Ocean Bottom Implanted Tiltmeter (OBIT) on the northwest shoulder of Erimo seamount, in the Kuril Trench, at a depth of $3930 \mathrm{~m}$. They were able to find bare rocks and to cement the sensing unit successfully using French deep submersible Nautile. Experiments were also attempted to measure changes in baseline length under the sea using acoustic waves (e.g., Fujimoto et al., 1996; Yabuki et al., 1997). Fujimoto et al. (1996) tested a seafloor acoustic ranging system, which uses M-sequence acoustic signals, in the Sagami bay at a depth of about $1400 \mathrm{~m}$. Their experimental results show that the tidal variation of water temperature on the seafloor is about $0.2^{\circ} \mathrm{C}$, which corresponds to an acoustic range of about $1 \mathrm{~m}$ at the baseline length of $1.5 \mathrm{~km}$. The tidal effect correction, using water temperature measured at both ends of the baseline, can reduce the root mean square residuals of the distance to $7 \mathrm{~cm}$. They pointed out that monitoring of water temperature is necessary for precise acoustic ranging.

The observation systems described above are basically independent from on-land observations. If seafloor observations are connected with on-land observations, such as GPS observation in the large area (e.g., Geographical Survey Institute, 1996), we can understand the tectonic processes more accurately. Precise positioning of seafloor reference sites relative to reference sites on land is necessary to integrate the seafloor measurements with on-land observations.

We are developing a seafloor positioning system with a GPS-acoustic link. This system is designed to determine a relative position of a seafloor reference point to an on- 


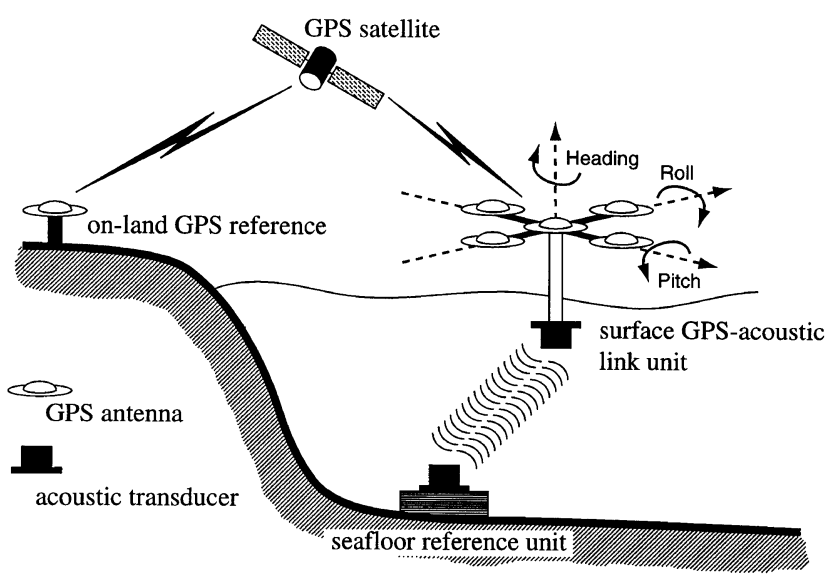

Fig. 1. System configuration of the seafloor positioning with GPS-acoustic link. The location of the surface GPS-acoustic link unit is determined relative to the on-land GPS reference site. The ranges between the seafloor and surface are measured using the acoustic ranging technique.

land reference. The crustal movements detected by repeated seafloor position observations can integrate with on-land observations in a same global reference frame. This paper presents preliminary experiments of this system.

\section{System Configuration}

A seafloor positioning system with a GPS-acoustic link consists of two main components; (1) surface positioning by differential GPS and (2) precise acoustic ranging using the M-sequence between the surface and seafloor references (Fig. 1). The positions of seafloor references are determined from these observations and sound-speed structure model of the seawater. This system is basically the same as that described by Purcell et al. (1991) and Spiess and Hildebrand (1995). Their system used a circular acoustic transponder array installed on the seafloor and performed acoustic ranging between sea surface and seafloor above the center of the transponder array. The horizontal center of the array can be determined independently of the vertical variation of the underwater sound speed. Their system assumes that internal geometry of the transponder array is unchanged between repeated observations. A change of the array geometry is detected as a change of the array center position. In the seafloor positioning experiments presented in this paper, each transponder position on the seafloor is determined from GPS and acoustic measurements. The surface measurements are performed around a seafloor reference and a seafloor position is determined by a way like a hypocenter determination. This way of seafloor positioning does not need a rigid transponder array between repeated observations though it is difficult to remove the effect of sound speed variation.

A surface GPS-acoustic link unit is equipped with a GPS antenna array and an acoustic transducer (Fig. 2). An antenna array consisting of five GPS antennas is attached to the top end of the surface unit to observe surface unit positions and attitude on the water. The surface position is determined by the kinematic GPS analysis of the center antenna relative to the on-land reference. An Ashtech Z-Surveyor is used for the receiver of the center antenna. The attitude of the

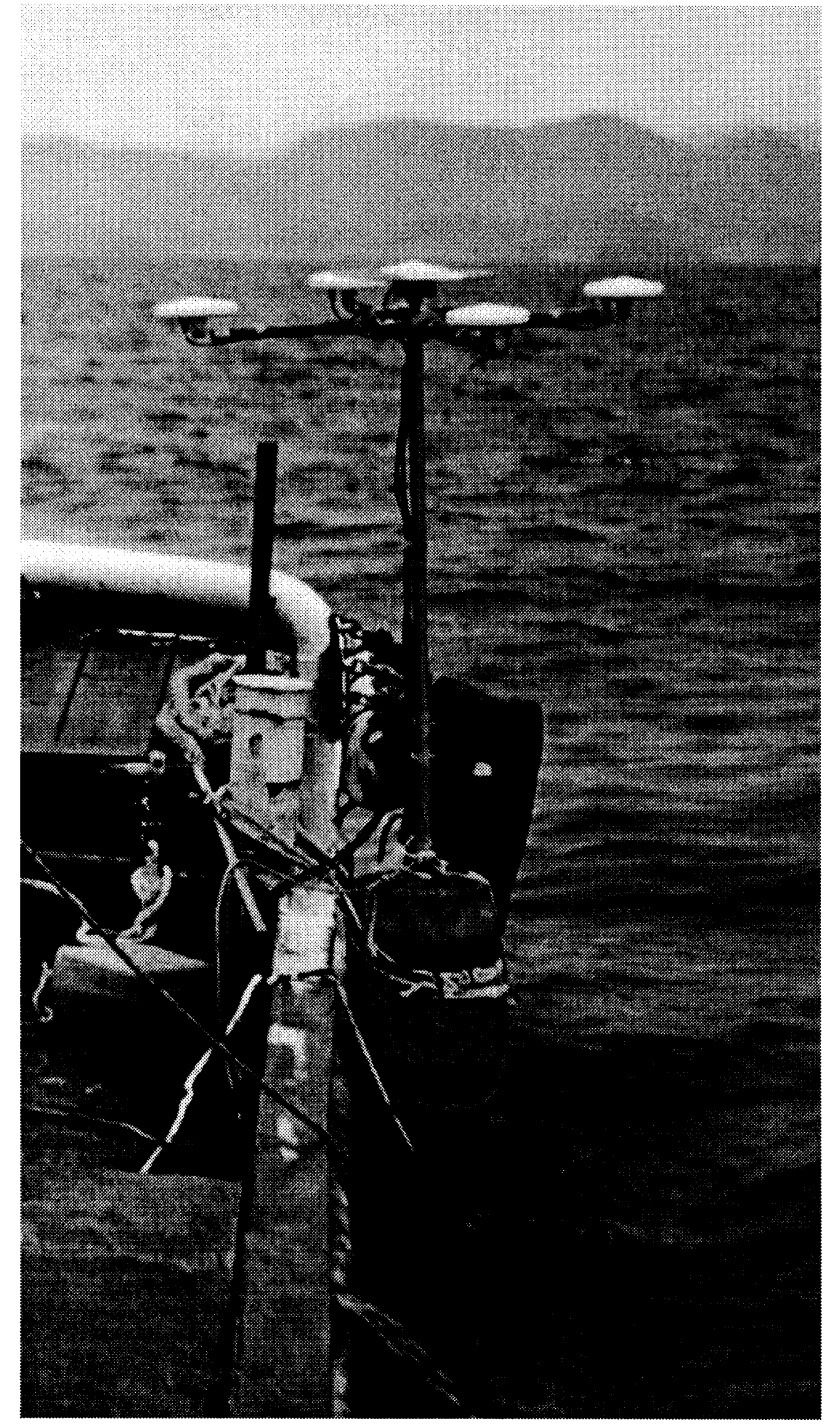

Fig. 2. The surface GPS-acoustic link unit. A GPS antenna array is attached to the top end of the pole. The center antenna is used for the positioning and the others for the attitude determination. An acoustic transducer is below the sea-surface. It is attached to the bottom end of the pole about $5 \mathrm{~m}$ beneath the antenna array.

surface unit is observed by Ashtech Attitude Determination Unit ADU2. This unit is designed to provide precise real-time heading, pitch and roll along with three-dimensional position and velocity for static or dynamic platforms. The sampling interval of the center antenna is 1 second, and attitude update interval is 0.5 second. An acoustic transducer is assembled at the bottom end of the pole about $5 \mathrm{~m}$ beneath the antenna array. This transducer is used for the precise acoustic ranging to the seafloor units. The position of surface transducer can be estimated with a decimeter accuracy for a $100-\mathrm{km}$ baseline from the kinematic position and the attitudes, which are based on the GPS observations (Obana, 1998).

The seafloor units used for the seafloor references are composed of two 17-inch-diameter glass spheres (Fig. 3). Since the experiments in this study are preliminary, seafloor units are designed to be retrievable after the experiment. The seafloor units are equipped with a pressure sensor, a water thermometer and an acoustic transducer. The pressure sen- 


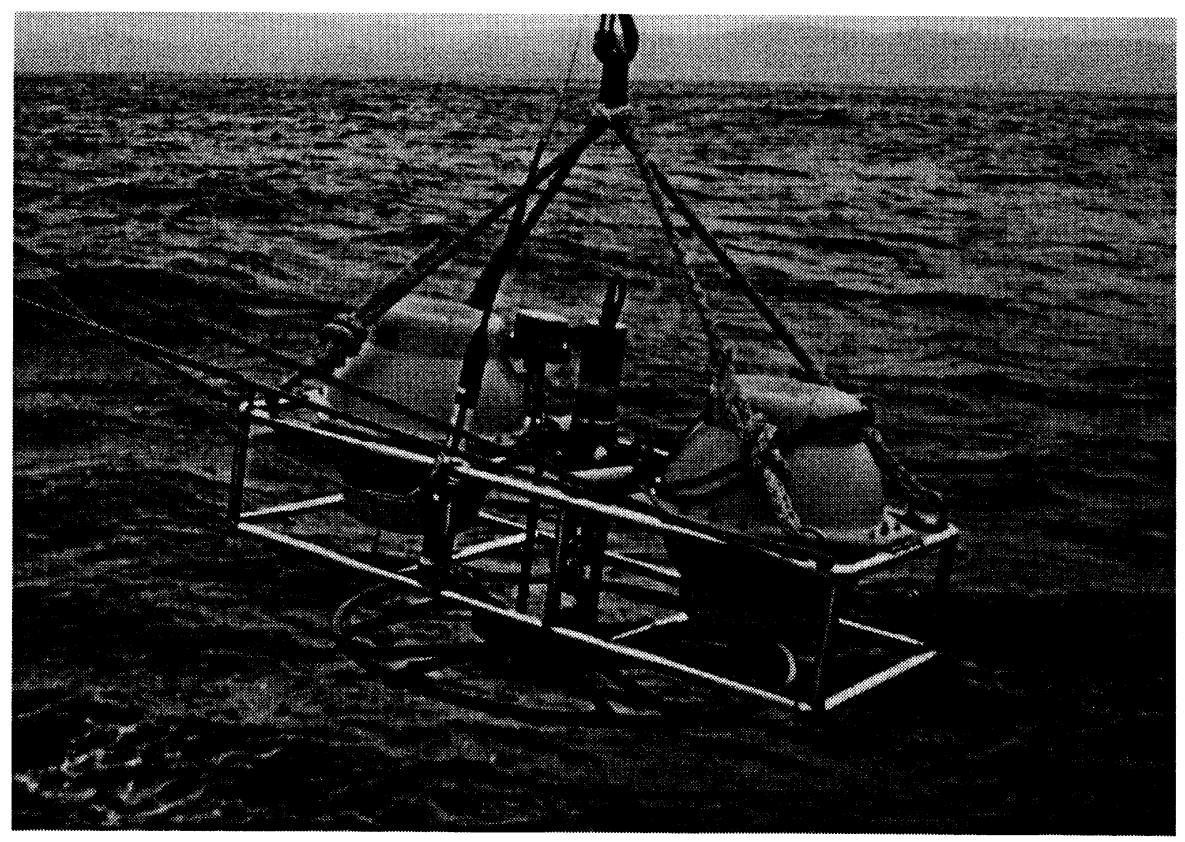

Fig. 3. Photo of a seafloor reference unit. Each unit consists of two pressure glass spheres. A water thermometer and a pressure transducer are included. These seafloor units were retrieved after the experiment.

(a) Received signal

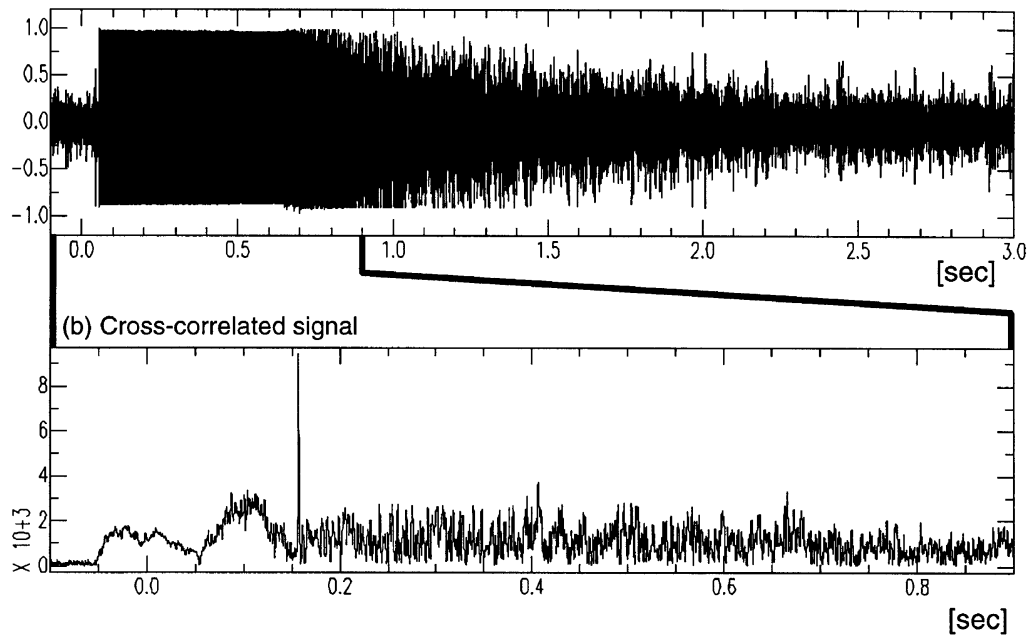

Fig. 4. (a) An example record of acoustic signal modulated by 7th-order M-sequence. (b) Its cross-correlated signal. This example has a 99.9 msec unmodulated part before the M-sequence signal.

sor data are transmitted from the seafloor reference units to the surface unit using an acoustic data transmission system. The water temperatures measured by the thermometer are collected after the retrieval of the seafloor units.

The precise acoustic ranging between surface and seafloor units are carried out using the acoustic wave coded by the maximumlength sequence, which is called the "M-sequence". The M-sequence is a pseudo-random code that is effective in the pulse compression (Nagaya, 1995). The acoustic travel time between the surface and seafloor references are measured using this technique. This is a standard procedure in precise acoustic measurements (e.g., Takeuchi, 1991; Fujimoto et al., 1995; Obana et al., 1999).
This system generates acoustic waves with a frequency of about $10 \mathrm{kHz}$ as the carrier wave. In this system, a one-bit signal is made from 8 cycles of carrier wave, and the digital code, such as 1 or -1 , is defined by the phase modulated by 0 or $\pi$ radian. This digital wave is coded by 7 th-order Msequence, which consists of $127\left(=2^{7}-1\right)$ bits digital code. The travel time is obtained by detecting the peak of the crosscorrelation values between transmitted and received signals. Figure 4 is an example record of the M-sequence acoustic signal received by surface unit and its cross-correlated signal. This example signal was transmitted by a seafloor unit in the shallow sea at a depth of about $60 \mathrm{~m}$. Though the received signal includes some multiple arrivals, first arrival time is 


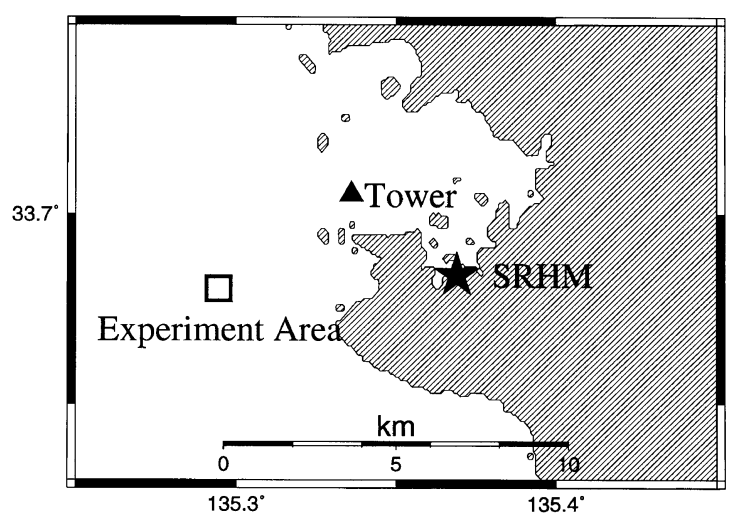

Fig. 5. Map around the experiment area. The solid star indicates the GPS on-land reference site SRHM. The solid triangle is the observation tower of the Shirahama Oceanographic Observatory. The measurements for the seafloor positioning are done in the rectangular area, which is referred to Fig. 7.

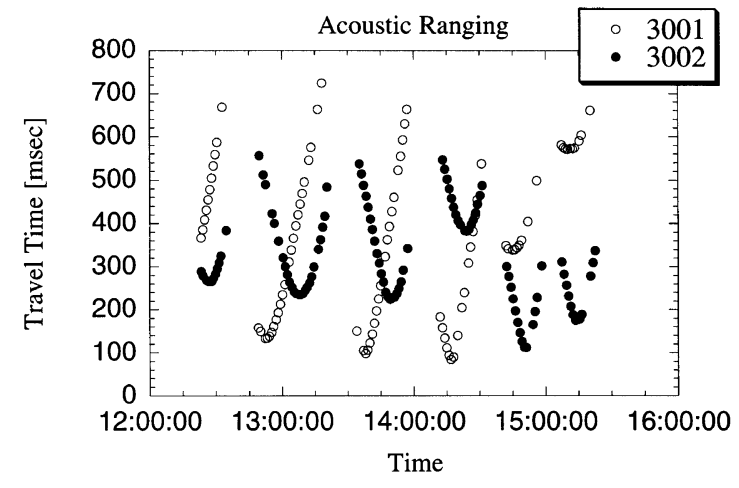

Fig. 6. The acoustic two-way travel times between seafloor references and the surface unit. The measurements for unit 3001 and 3002 are indicated by open and solid circles, respectively. Horizontal axis represents the time of measurement.

clearly detected as the highest peak in the cross-correlated record.

The acoustic signal is transmitted from the surface unit to the seafloor references. The seafloor units receive the signal and detect its arrival time. After a given interval time from the arrival, the seafloor units send back the signal to the surface. The surface unit detects the arrival times of the returned signal and calculates the two-way acoustic travel time between the surface and seafloor units from the known transmission time of the signal at the surface and interval time at the seafloor. If we can measure two-way travel times, the range is determined with a given sound-speed profile. The positions of seafloor references are estimated from these GPS and acoustic observations and sound-speed structure models of the seawater.

\section{Experiment at Shallow Depth \\ 3.1 Experiment procedure}

The positioning experiment of the seafloor references was conducted on October 21, 1998. It was performed off Shirahama, Wakayama Prefecture, southwest Japan (Fig. 5). The depth of the experiment area is about 60 to $70 \mathrm{~m}$. The SRHM in Fig. 5 designates the GPS on-land reference site.

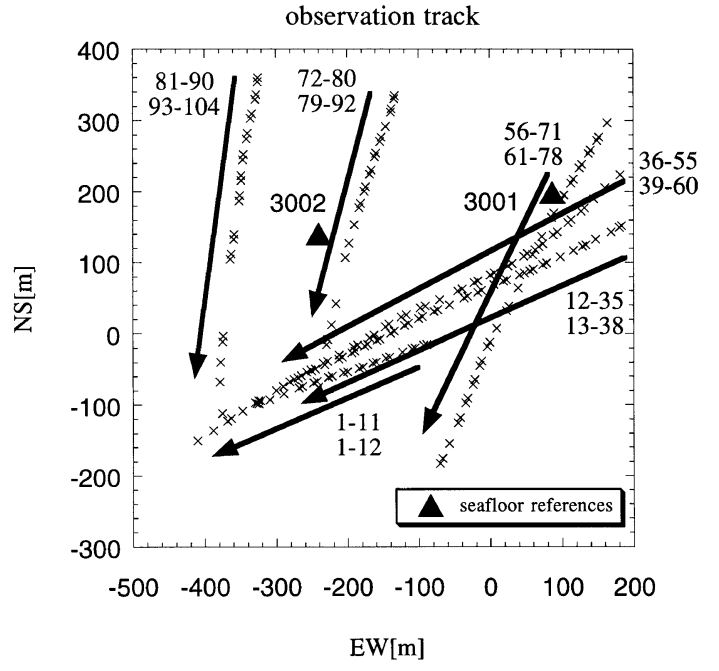

Fig. 7. Observation tracks in the rectangular region in Fig. 5. Crosses indicate positions where acoustic measurements were carried out. The solid arrows indicate the drifting direction of the ship. The numerals next to arrows are the sequential number of acoustic measurement done at each observation series. The upper and lower numbers are for unit 3001 and unit 3002, respectively. The solid triangles indicate the location of the seafloor units.

The location of SRHM was determined using Bernese GPS Software Version 4.0 with precise ephemerides produced by International GPS Service (T. Nakano, personal communication, 1998). The GPS observation (for position and attitude) had been performed continuously during the experiment cruise of about 7 hours. The surface position was analyzed using the Ashtech Precise Differential GPS Navigation and Surveying Software (PNAV).

Before the beginning of acoustic range measurements, three seafloor reference units were dropped by free fall onto the seafloor from the ship, with a spacing of a few hundreds meters. The seafloor positioning observations were performed for two seafloor units of these, which are unit 3001 and 3002. The observed two-way travel times are shown in Fig. 6.

When the acoustic observation was carried out, the surface unit transducer was set below the sea surface and the antenna array was attached to the upper end of the pole. The ship declutched and drifted. When the ship drifted with the sea current too far away from the seafloor references, the ship was moved toward the upper direction of the current after the surface transducer was lifted up onto the ship. Hence, the acoustic observation was composed of some continuous sampling series. The observation points of the surface unit, where the acoustic signal was transmitted, are shown in Fig. 7. Six series of continuous observation were made during the experiment. The total number of successful acoustic measurements is 90 for unit 3001 and 103 for unit 3002, respectively. The measurements for each seafloor unit were done almost evenly. The seafloor reference units were retrieved after the experiment.

\subsection{Determination of seafloor reference positions}

In the seafloor position analysis, it is necessary to know the position of the surface unit's transducer and sound-speed profile in the seawater along the acoustic ray path between 
Table 1. The locations of seafloor reference units in WGS-84 in the shallow depth experiment.

\begin{tabular}{|c|c|c|c|c|c|c|}
\hline & \multicolumn{3}{|c|}{ Sound Speed: Model I } & \multicolumn{3}{|c|}{ Sound Speed: Model II } \\
\hline No. & & Position & Error $(\mathrm{cm})$ & & Position & Error $(\mathrm{cm})$ \\
\hline \multirow{3}{*}{3001} & $\mathrm{~N}$ & $33^{\circ} 40^{\prime} 54.1451^{\prime \prime}$ & 13.79 & $\mathrm{~N}$ & $33^{\circ} 40^{\prime} 54.1444^{\prime \prime}$ & 13.98 \\
\hline & $\mathrm{E}$ & $135^{\circ} 17^{\prime} 48.8436^{\prime \prime}$ & 18.23 & $\mathrm{E}$ & $135^{\circ} 17^{\prime} 48.8290^{\prime \prime}$ & 18.48 \\
\hline & & $-28.483 \mathrm{~m}$ & 24.73 & & $-28.226 \mathrm{~m}$ & 25.24 \\
\hline \multirow{3}{*}{3002} & $\mathrm{~N}$ & $33^{\circ} 40^{\prime} 52.3221^{\prime \prime}$ & 12.30 & $\mathrm{~N}$ & $33^{\circ} 40^{\prime} 52.3199^{\prime \prime}$ & 12.21 \\
\hline & $\mathrm{E}$ & $135^{\circ} 17^{\prime} 36.0534^{\prime \prime}$ & 12.49 & $\mathrm{E}$ & $135^{\circ} 17^{\prime} 36.0593^{\prime \prime}$ & 12.40 \\
\hline & & $-34.506 \mathrm{~m}$ & 26.50 & & $-34.097 \mathrm{~m}$ & 26.60 \\
\hline
\end{tabular}

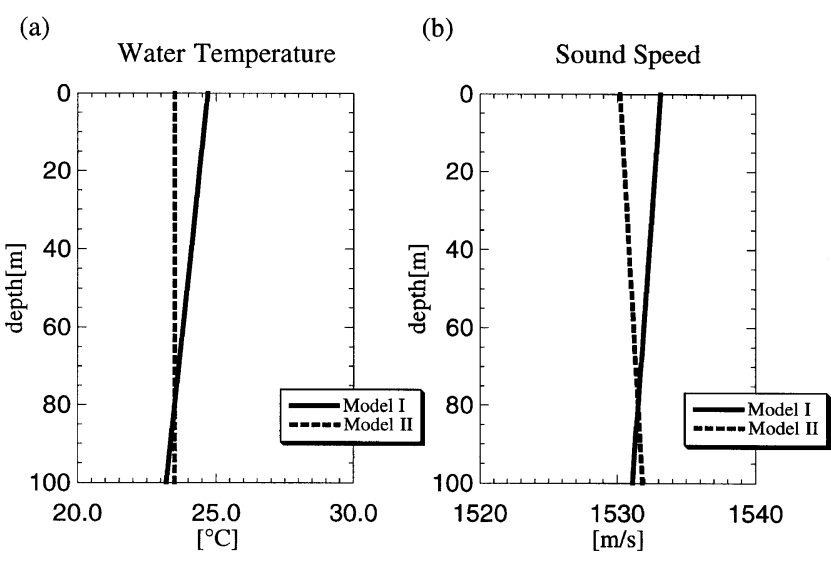

Fig. 8. (a) Two water temperature profiles in the seawater used for the sound-speed calculation. (b) Two sound-speed models derived from the water temperature profiles. The salinity is assumed to be 34.6 parts per thousand. The sound-speed profiles are calculated by the equation of Mackenzie (1981)

the surface and the seafloor units. The position of the surface transducer is estimated from the results of kinematic positioning based on the differential GPS and the attitude provided by $A D U 2$. Since the times of transmission and the reception of the acoustic signal are known, the transducer position can be interpolated by the cubic-spline from the position and attitude data based on GPS.

The sound-speed in the seawater depends on the water temperature, salinity and pressure. Each seafloor reference unit is equipped with a water thermometer in the present experiment. And more, the water temperatures at several shallow depths are measured at an oceanographic observation tower of the Shirahama Oceanographic Observatory, Disaster Prevention Research Institute, Kyoto University (S. Serizawa, personal communication, 1998). The observatory tower is about $4 \mathrm{~km}$ away from the experiment area (Fig. 5). Although the detail of the water temperature variation is not known, the sound-speed model for the analysis is based on these observations.

The salinity data is necessary to calculate the the soundspeed. We refer to several CTD (Conductive-TemperatureDepth meter) or STD (Salinity-Temperature-Depth meter) profiles observed formerly around the experiment area, and (a)

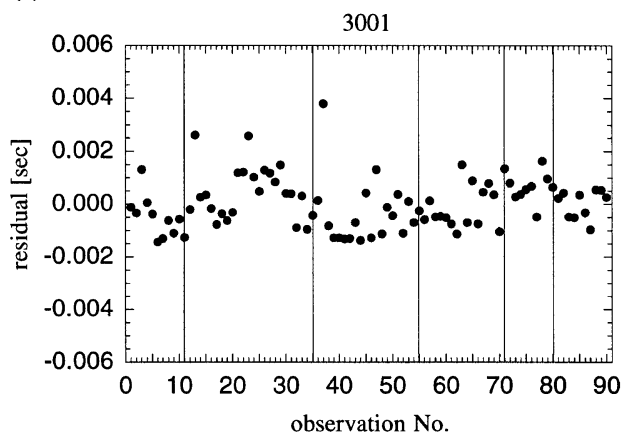

(b)

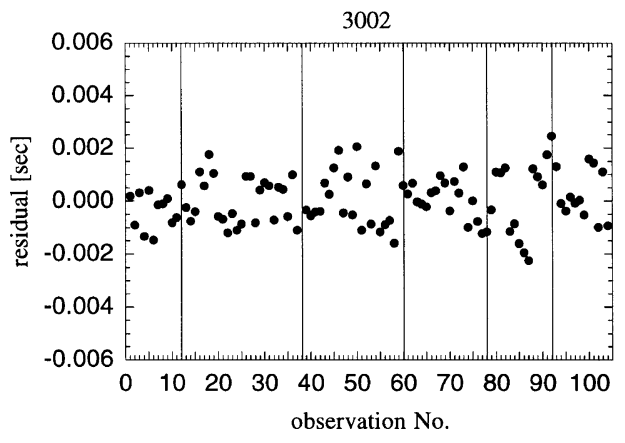

Fig. 9. Two-way travel time residuals for each acoustic measurement. These are based on the location for sound-speed Model I. (a) The residuals for unit 3001. (b) The residuals for unit 3002. Horizontal axis represents the sequential numbers of acoustic observations. Vertical line in each panel separate continuous observation series.

assume that the salinity is 34.6 parts per thousand at all depths.

We construct two models of water temperature profiles (Fig. 8(a)). Model I is that the water temperature is $24.7^{\circ} \mathrm{C}$ at the surface and $23.5^{\circ} \mathrm{C}$ at the depth of $80 \mathrm{~m}$. The water temperature at other depths is given by the linear interpolation or extrapolation of these temperatures. Model II has a uniform water temperature of $23.5^{\circ} \mathrm{C}$ at all depths. The sound-speed profiles are calculated by the equation of Mackenzie (1981) (Fig. 8(b)).

It is necessary to know the sea surface height for the linkage of the seafloor positioning data measured in global coordinate and underwater data for sound-speed model measured 


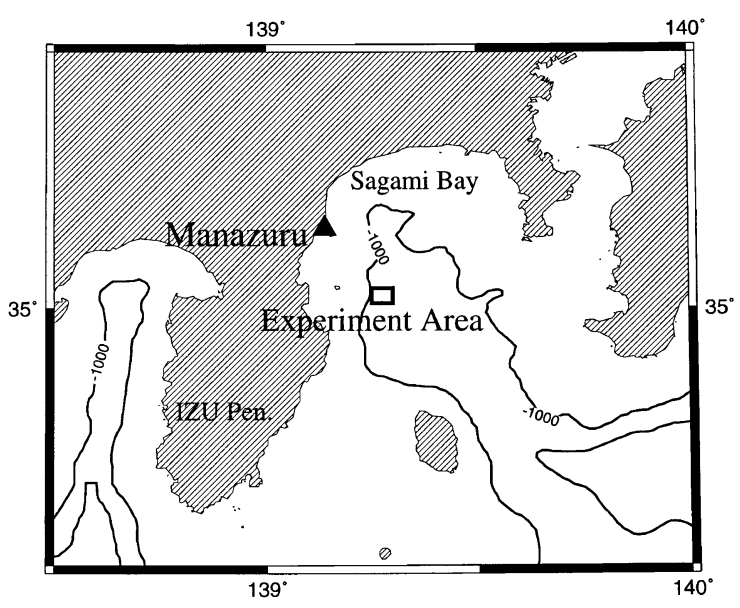

Fig. 10. Map of the experiment area of the seafloor positioning in the deepsea. The rectangle is the map area of Fig. 11. A solid triangle indicates the on-land GPS reference site "Manazuru", which is operated by the Hydrographic Department, Maritime Safety Agency, Japan.

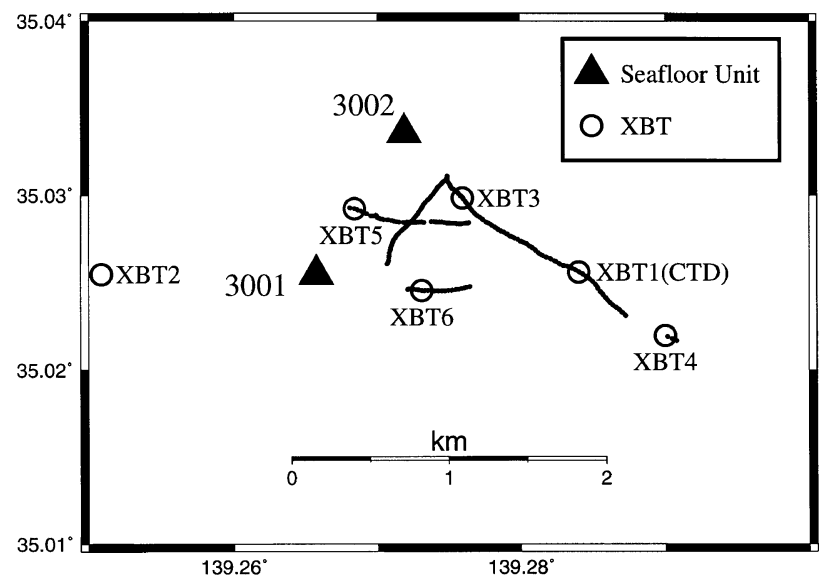

Fig. 11. Observation points for the seafloor positioning in the rectangular region in Fig. 10. Solid triangles indicates the ship positions when the seafloor units were dropped. The locations of the XBT measurements are indicated by open circles. Positions, where the acoustic measurements were performed, are indicated by dots.

in depth from sea surface. The mean sea level is assumed to be $38.2 \mathrm{~m}$ around the experiment area, which is derived from the geoid model (Fukuda, 1994).

The locations of the seafloor reference for the two soundspeed profiles are determined individually as to minimize the two-way travel time residual using the least square method. The obtained position in the WGS- 84 reference frame, and their standard errors of the position are shown in Table 1. The accuracies of the position of both units are almost the same. There is little difference between the position errors for two sound-speed models. The residuals for each acoustic measurement are shown in Fig. 9 with their sequential number. These are based on the estimation for sound-speed Model I. The residual distributions are also the same for different sound-speed structures. The root mean square residuals of two-way travel time are less than $1.0 \mathrm{msec}$ for both units in both sound-speed models.

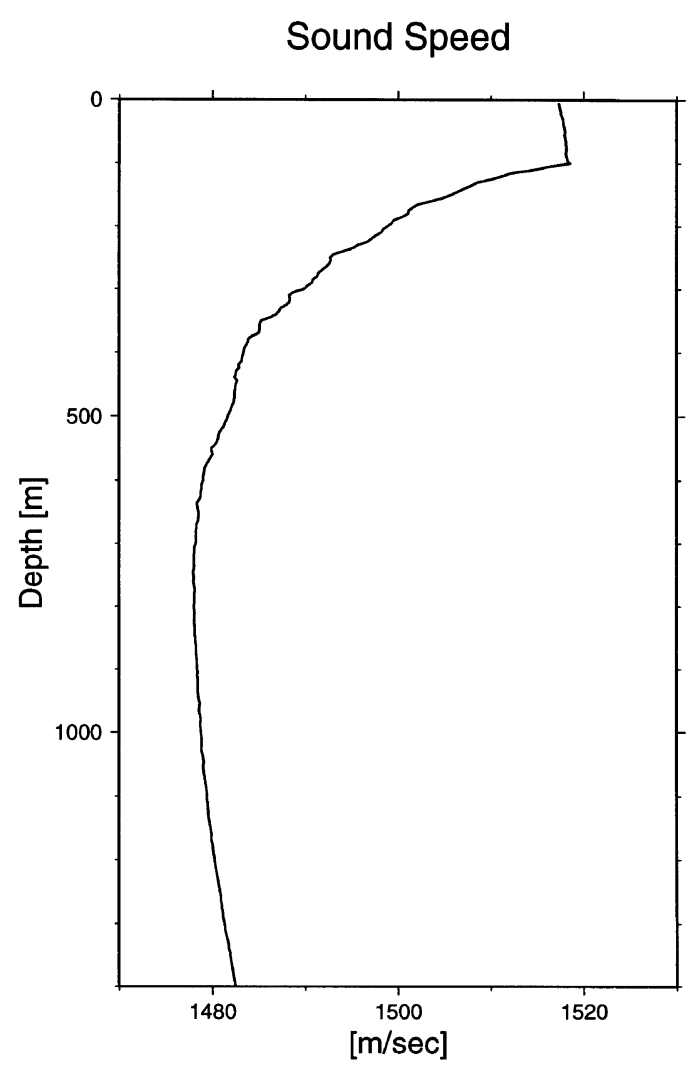

Fig. 12. Sound-speed profile used in the seafloor position analysis of the deepsea experiment. This is based on the salinity and water temperature profiles derived from the CTD observation. Sound-speed profile is calculated using the equation of Del Grosso (1974).

\section{Deepsea Experiment}

\subsection{Experiment procedure}

Another experiment in the deepsea was performed on December 8, 1998 in the Sagami Bay, Central Japan (Fig. 10). The depth of the experiment area is about $1300 \mathrm{~m}$. This experiment was performed on the survey vessel Meiyo, which belongs to the Hydrographic Department, Maritime Safety Agency, Japan (JHD). Instruments of the surface and seafloor units are the same at the previous experiment at shallow depths. The GPS observation site "Manazuru", which is about $20 \mathrm{~km}$ away from the experiment area, was used as the on-land reference site. This site is operated by JHD and Trimble-4000SSE is used as the receiver (M. Fujita, personal communication, 1998).

The procedure of the acoustic ranging was the same at the previous experiment. The survey vessel drifted during the acoustic measurements. All seafloor units were dropped from the ship before the experiment and retrieved after the experiment. The CTD and XBT (Expendable Bathy Thermograph) observations were carried out to obtain the data for sound-speed structure.

The observation points of the surface unit, where the acoustic signal was transmitted are shown in Fig. 11. The location of the XBT observations are also indicated in this figure. The observation by the CTD was carried out before the installation of the seafloor reference units. The location of the CTD observation is almost the same at the XBT1 in Fig. 11. The observation of XBT1 was performed immediately after the 
[a]

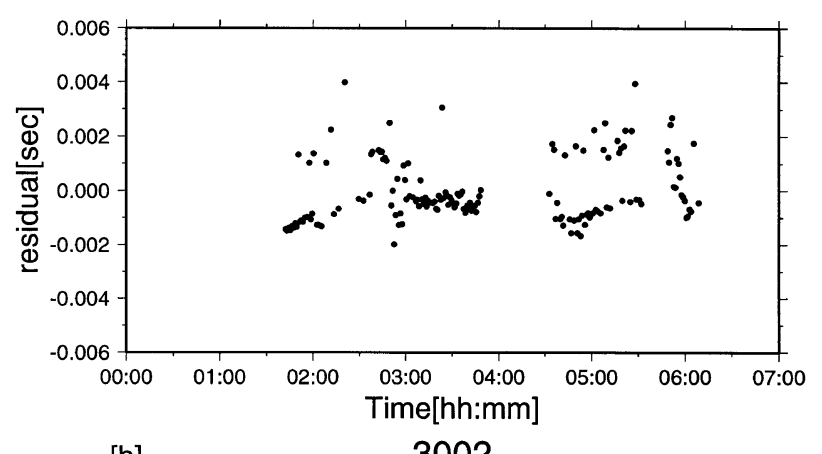

[b]

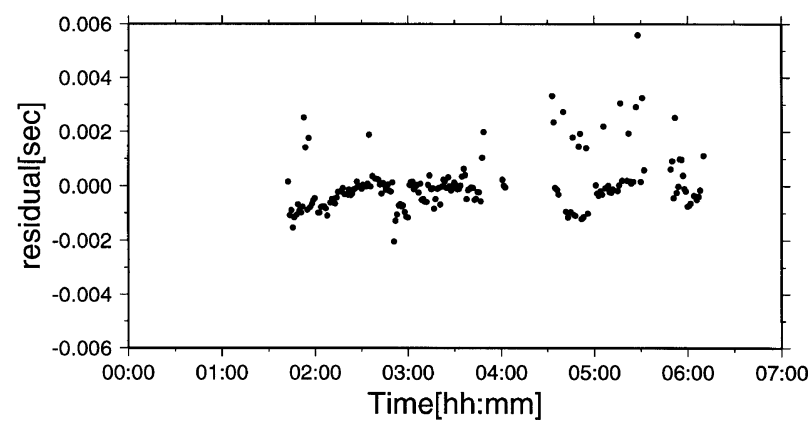

Fig. 13. Two-way travel time residuals for each acoustic measurement. (a) The residuals for the unit 3001. (b) The residuals for the unit 3002. Horizontal axis represents the time when the acoustic measurements were performed.

CTD observation for a comparison. Total number of the obtained two-way travel times is 158 and 189 for unit 3001 and 3002 , respectively.

\subsection{Determination of seafloor reference positions}

Although the system accuracy of the XBT is not sufficient for the precise estimation of the sound-speed, there is no remarkable trend in the water temperature profiles. In this analysis, we use the stationary 1-D profile for the sound-speed structure (Fig. 12). This profile is calculated by the equation of Del Grosso (1974). The profiles of water temperature and salinity, which are used in the sound-speed calculation, are based on the CTD observation and we extrapolate them smoothly to deeper part.

The sea surface height is assumed to be $37.34 \mathrm{~m}$ from the geoid model of Fukuda (1994). The locations of two seafloor units are determined to minimize the two-way travel time residual using the least square method. The obtained locations of each unit and their standard errors are shown in Table 2. Although the estimated errors for unit 3001 are a little larger than the errors for unit 3002, there is no significant difference between both position accuracies. The residuals for each acoustic measurement are shown in Fig. 13. The root mean square residuals of two-way travel time are $1.0 \mathrm{msec}$ approximately for both seafloor units.

\section{Discussion}

In this section, we discussed the results of two preliminary experiments and improvements of a present seafloor positioning system for more accurate measurements. The locations
Table 2. The locations of seafloor reference units in WGS-84 in the deepsea experiment.

\begin{tabular}{rrrr}
\hline No. & \multicolumn{2}{c}{ Position } & Error $(\mathrm{cm})$ \\
\hline \multirow{2}{*}{3001} & $\mathrm{~N}$ & $35^{\circ} 01^{\prime} 31.2963^{\prime \prime}$ & 15.45 \\
& $\mathrm{E}$ & $139^{\circ} 15^{\prime} 54.8877^{\prime \prime}$ & 22.49 \\
& & $-1327.125 \mathrm{~m}$ & 9.59 \\
\hline \multirow{2}{*}{3002} & $\mathrm{~N}$ & $35^{\circ} 01^{\prime} 59.8042^{\prime \prime}$ & 12.18 \\
& $\mathrm{E}$ & $139^{\circ} 16^{\prime} 18.2238^{\prime \prime}$ & 17.74 \\
& & $-1329.239 \mathrm{~m}$ & 9.59 \\
\hline
\end{tabular}

of the seafloor reference units are determined in the WGS- 84 reference frame in both experiments. The standard errors of seafloor positions are about 10 to $20 \mathrm{~cm}$ in each direction.

In the first shallow depth experiment, the positioning errors are about $15 \mathrm{~cm}$ in horizontal components and $25 \mathrm{~cm}$ in vertical components for both units. We assumed 1-D soundspeed profiles for the acoustic ranging. The standard errors of seafloor reference positioning are almost the same for two different sound-speed structures. Available observations of water temperature and salinity are insufficient in spatial distribution for determining fine sound-speed structures. In addition to this, it is clear that the actual sound-speed structure varied with time from the water temperature observations. The water temperature at the seafloor dropped more than $1{ }^{\circ} \mathrm{C}$ during the experiment. On the other hand, water temperature at shallow depth observed $4 \mathrm{~km}$ away from the experiment area rose about 0.4 to $0.7^{\circ} \mathrm{C}$. According to the sound-speed equation described by Mackenzie (1981), the sound-speed is expected to increase about $2.7 \mathrm{~m} / \mathrm{sec}$ with a $1^{\circ} \mathrm{C}$ rise in water temperature for at about $20^{\circ} \mathrm{C}$. This sound-speed variation is equal to about $0.9 \mathrm{msec}$ for the acoustic two-way travel time of 0.5 second. It is difficult to explain the residuals only by a simple model of sound-speed.

The two-way travel time residuals do not change randomly in time and has some systematic trends (Fig. 9). If the measurement was done correctly and sound-speed structure is assumed adequately, the residual should distribute randomly. The systematic distribution implies that there is a systematic difference between the assumed and real sound-speed structure.

The accuracies of the seafloor positioning in the deepsea experiment are basically on the same level with the shallow depth experiment. The obtained depths are about $10 \mathrm{~m}$ shallower than the bathymetrical chart. Although we examine several sound-speed profiles based on the CTD and XBT observations, the difference of the depths remains in all cases.

In the deepsea experiment, the two-way travel time residuals show some irregular changes and the same systematic trends for both units (Fig. 13). It is thought that these irregular changes occurred when cross correlation functions of observed acoustic wave have several peaks with the same level intensity. In this deepsea experiment, several wave forms of acoustic signal were recorded. There is a minor correlation peak after the highest peak in some records. These 
sub-peaks, which are not direct arrivals of the signal, relate to the large positive residuals.

When the location of the seafloor unit 3002 is recalculated from the selected data except for some acoustic measurements which have a large positive residual, the root mean square of the two-way travel time residuals are less than 0.5 msec. The standard errors for the recalculated location are 9, 12 and $6 \mathrm{~cm}$ in NS, EW and UD components, respectively. The same systematic trends of both seafloor units mean that the assumed sound-speed structure model is different from the real structure at shallow depths, where the acoustic ray paths are basically the same for both units. We can expect to reduce the uncertainties of sound-speed structures using these systematic trends. The simultaneous determination for the seafloor reference locations and sound-speed structures is necessary for a more accurate seafloor positioning. It is effective to multiplex the acoustic measurements to several seafloor references for this.

The results of these experiments indicate the possibility of positioning with an accuracy on order of $10 \mathrm{~cm}$. It is known that large earthquakes have occurred repeatedly along the Nankai Trough (e.g., Ando, 1975). The co-seismic crustal deformation from these earthquakes are expected to amount to several meters in this area. When the seafloor references are set on the source regions of these large interplate earthquakes, we can expect to detect their co-seismic deformations. If the crustal deformation of these earthquakes are measured directly, they will make a significant contribution to understanding the cyclic process of large earthquakes related to the subduction.

It is necessary to locate the seafloor reference with a few $\mathrm{cm}$ accuracy for observing the inter- and post-seismic deformations during the cyclic process of large earthquakes. It is difficult to attain this accuracy only by one-to-one acoustic ranging between seafloor and surface units without fine sound-speed profiles. To locate the horizontal center of the circular array of acoustic transponders, is one of the effective ways to reduce the effect of the approximate knowledge of the sound speed (Spiess et al., 1998).

In both experiments presented in this paper, surface observation points are not selected freely because the acoustic measurements cannot be performed when the vessel clutches in due to acoustic noises. The distribution of the surface observations are related to the shape of the error ellipsoid for the estimated location of the seafloor references. It is necessary to increase the mobility of the observations. One effective way is to use an acoustic transducer attached to the bottom of a vessel. This improvement makes it easy to perform acoustic ranging above the point of a center of acoustic transponder array. There is another problem in the acoustic ranging. A surface unit position at a transmission and reception of acoustic signal is assumed as a position at a beginning of acoustic signal. However, the actual signal length is about $100 \mathrm{msec}$. When a surface unit drifts about 2 knots (approx. $1 \mathrm{~m} / \mathrm{sec}$ ), a surface unit can move about $10 \mathrm{~cm}$ during the period of the transmission and reception of signal. The positioning error includes the ambiguity of surface position caused by a length of acoustic signal. Though a use of higher frequency carrier wave and lower order M-sequence can shorten the length of acoustic signal, it is thought that a possible measurement dis- tance and accuracy of acoustic ranging decrease. An acoustic signal is selected carefully under consideration to distances between surface and seafloor units and an effect of movements of a surface unit. A surface unit movements change a frequency of a signal due to a doppler shift. The effect of this is not considered in the experiments described in this paper. It is necessary to correct the effect of ambiguity caused by surface unit movements.

In the seafloor research observations, use of the ocean bottom cable have been realized (e.g., Momma et al., 1997; Kasahara et al., 1998). The flexibilities of the seafloor observation become large by using the cables. The use of the cable is effective for the long-term and highly-developed observations, which include the seafloor positioning.

\section{Conclusion}

We described a development of seafloor positioning system with GPS and acoustic linkage and its preliminary experiments in this paper. This system aims to observe crustal movements related to tectonic processes on the seafloor. The results of the shallow and deepsea experiments show that seafloor position can be estimated with an accuracy on order of $10 \mathrm{~cm}$ using our system. In these position analyses, depth-dependent 1-D sound-speed structure models were used. However, the observed water temperatures show variations in time and space at shallow depths. The two-way travel time residuals show some systematic trends. It is thought that these trends relate to a change of underwater sound-speed structure. It is important to obtain the "real" sound-speed structure for a more precise seafloor positioning. The simultaneous determination for the seafloor reference locations and sound-speed structures is necessary for a more accurate observation.

When the seafloor references are set on the source regions of subduction large earthquakes, we can expect to detect the coseismic deformations of large earthquakes. To observe more details of tectonic processes, the positioning accuracy must be decimeter level at least. Improvements of the seafloor positioning system and measurement procedure is necessary for more accurate seafloor positioning.

Acknowledgments. We would like to acknowledge the assistance of Shigemitsu Matsuo, Shigeatsu Serizawa, Yoshinobu Hoso, Takehide Nakano and Keiichi Tadokoro. The experiment in the Sagami Bay was the joint research with Hydrographic Department, Maritime Safety Agency, Japan. Dr. Akira Asada and Dr. Masayuki Fujita provided the GPS and CTD data of this experiment. The instruments of the seafloor reference units were produced by Hideyuki Murakami and the staffs of Kaiyo Denshi Co., Ltd. We also thank Dr. John Hildebrand and an anonymous referee for their careful reviews. This study was funded by the Science and Technology Agency and the ministry of Education, Science, Sports and Culture, Japan. One of the authors (K.O.) was supported by Research Fellowships of the Japan Society for the Promotion of Science for Young Scientists.

\section{References}

Anderson, G., S. Constable, H. Staudigel, and F. K. Wyatt, A seafloor longbaseline tiltmeter, J. Geophys. Res., 102, 20,269-20,285, 1997.

Ando, M., Source mechanisms and tectonic significance of historical earthquakes along the Nankai Trough, Japan, Tectonophys., 27, 119-140,1975.

Del Grosso, V. A., New equation for the speed of sound in natural waters (with comparisons to other equations), J. Acoust. Soc. Am., 56, 1084 $1091,1974$. 
Fujimoto, H., T. Kanazawa, and H. Murakami, Experiment on precise seafloor acoustic ranging-a promising result of observation-, J. Seism. Soc. Jpn., 48, 289-292, 1995 (in Japanese).

Fujimoto, H., T. Kanazawa, and H. Murakami, Seafloor acoustic ranging and the effect of temperature variation, in Gravity, Geoid and Marine Geodesy International Symposium, Vol. 117 of International Association of Geodesy Symposia, edited by J. Segawa, H. Fujimoto, and S. Okubo, pp. 690-695, Springer, 1996.

Fukuda, Y, Improvements of a geoid model around Japan, Monthly Earth, 16, 611-616, 1994 (in Japanese).

Geographical Survey Institute, Results of the continuous GPS observation all over Japan, Report of the Coordinating Committee for Earthquake Prediction, 56, 651-654, 1996 (in Japanese).

Heki, K., S. Miyazaki, and H. Tsuji, Silent fault slip following an interplate thrust earthquake at the Japan Trench, Nature, 386, 595-598, 1997.

Kasahara, J., H. Utada, T. Sato, and H. Kinoshita, Submarine cable OBS using a retired submarine telecommunication cable; GeO-TOC program, Phys. Earth Planet. Inter, 108, 113-127, 1998.

Mackenzie, K. V., Nine-term equation for sound speed in the oceans, $J$. Acoust. Soc. Am., 70, 807-812, 1981.

Momma, H., Y. Shirasaki, and J. Kasahara, The VENUS project-instrumentation and underwater work system, in Proceedings of International Workshop on Scientific Use of Submarine Cables, pp. 103-108, 1997.

Nagaya, Y., Basic study on a sea floor strain measurement using acoustic techniques, Report of Hydrographic Researches, 31, 67-76, 1995 (in Japanese with English abstracts).

Obana, K., Development of seafloor positioning system with GPS-acoustic link for crustal dynamics observation, $\mathrm{Ph}$. D. thesis, Kyoto University, 99 pp., 1998.
Obana, K., H. Katao, and M. Ando, Sea-floor positioning with global positioning system-acoustic link system, the Island Arc, 8, 245-258, 1999.

Purcell, G. H., Jr., L. E. Young, S. K. Wolf, T. K. Meehan, C. B. Duncan, S. S. Fisher, F. N. Spiess, G. Austin, D. E. Boegman, C. D. Lowenstein, C. Rocken, and T. M. Kelecy, Accurate GPS measurement of the location and orientation of a floating platform, Mar. Geod., 14, 225-264, 1991.

Sakata, S., S. Shimada, and T. Hamatsuki, Development of the ocean bottom tiltmeter(1), J. Geod. Soc. Jpn., 27, 75-84, 1981 (in Japanese with English abstract).

Shimamura, H. and T. Kanazawa, Ocean bottom tiltmeter with acoustic data retrieval system implanted by a submersible, Mar. Geophys. Res., 9, 237-254, 1988

Spiess, F. N. and J. A. Hildebrand, Employing geodesy to study temporal variability at a mid-ocean ridge, EOS, 76, 451,455, 1995.

Spiess, F. N., C. D. Chadwell, J. A. Hildebrand, L. E. Young, G. H Purcell, Jr., and H. Dragert, Precise GPS/Acoustic positioning of seafloor reference points for tectonic studies, Phys. Earth Planet. Inter, 108, 101112, 1998.

Takeuchi, T., A long-range and high-resolution underwater acoustic positioning system, Mar. Geod., 14, 225-231, 1991.

Yabuki, T., Y. Nagaya, A. Asada, F. Ono, and K. Tajiri, Development of a seafloor acoustic ranging system (SeaFAR): Preliminary results of long term trial experiment, JAMSTEC Journal of Deep Sea Research, Special Volume Deep Sea Research in Subduction Zones, Spreading Centers and Backarc Basins, 147-151, 1997.

K. Obana (e-mail: obanak@jamstec.go.jp), H. Katao, and M. Ando 